\title{
Effect of Terazosin on the Pharmacokinetics of Levofloxacin in the Rat Model of Prostatitis
}

\author{
H. FAN*, H. ZHENG AND Q. ZHANG \\ Department of Urology, the Second Hospital of Jilin University, Changchun 130041, China
}

Fan et al.: Effect of Terazosin on the Pharmacokinetics of Levofloxacin

\begin{abstract}
The primary objective of the present work was to investigate the effect of terazosin on the pharmacokinetics of levofloxacin in prostate, when combined therapy of terazosin hydrochloride and levofloxacin were applied to treat bacterial prostatitis in the rat. A total of 100 rats with bacterial prostatitis were randomized into the control group and the research group, with 50 rats in each group. Levofloxacin solution was injected intravenously to the rats of both groups. Terazosin hydrochloride solution was given by gavage to the rats of the research group, while solvent was administrated by gavage to the rats of control group. After drug administration, the rat prostate was harvested and homogenized and the levofloxacin concentration was analysed. The drug-time curves in both groups were accorded with two compartments model. Compared with the control group, the $t_{1 / 2 \beta}, C_{\max }$ and $\mathrm{AUC}_{0-12}$ was significantly higher in the research group. And there was significant difference in the levofloxacin concentration of prostate between both groups $(p<0.05)$. The levofloxacin concentration and distribution were significantly elevated by terazosin hydrochloride, which could improve the prognosis of prostatitis and obtain better therapeutic efficacy.
\end{abstract}

Key words: Rat experiment, terazosin, levofloxacin, prostatitis, pharmacokinetics, efficacy

Prostatitis, caused by complicated factors, is mainly characterized by urethral exciting symptom and chronic pelvic pain. As a common disease of urology surgery, prostatitis mostly occur in males less than $50 \mathrm{y}$ old $^{[1,2]}$. Currently, the incidence of prostatitis has increased. However, the specific causes of prostatitis have remained unknown. For nonbacterial prostatitis, the primary therapeutic target is to actively improve the clinical symptoms. A new categorization approach for prostatitis was advanced by National Institutes of Health (NIH) in 1995, which is as follows, type I refers to acute bacterial prostatitis in the traditional categorization method, type II refers to chronic bacterial prostatitis in the traditional categorization method, type III refers to chronic prostatitis/chronic pelvic pain syndrome and type IV refers to asymptomatic prostatitis ${ }^{[3-5]}$. Of those, the relatively common type is nonbacterial prostatitis.

Prostatitis (fig. 1) has complex causes and persistence course, which can happen recurrently and thus affecting the patient's quality of life to a varied degree. Single use of antibiotics to treat prostatitis requires long treatment course and the therapeutic results were not satisfactory. Therefore, combination therapy regimen is desirable to significantly promote the therapeutic efficacy. In this study, the effect of terazosin was explored on the pharmacokinetics of levofloxacin in the treatment of prostatitis, aiming to provide valuable evidence for clinical treatment. 
A total of 100 male pathogen-free Sprague Dawley rats were procured from the Animal Experimental Center of Chongqing Medical University were used in this study. The average weight of rats was $200.18 \pm 20.17 \mathrm{~g}$, ranging from 180-220 g. Standard strain of Escherichia coli (ATCC25922) used in this study was provided by the Department of Microbiology, Chongqing Medical University, which was formulated into a suspension with $1.8 \times 10^{7} \mathrm{CFU} / \mathrm{ml}$. The treatment is comprised of terazosin hydrochloride tablets (SECCO Pharmaceuticals, Batch No. 080617) and levofloxacin lactate injection (Zhejiang Pharmaceutical Co., Ltd. Xinchang Pharmaceutical Factory, Batch No. 081112). Equipment used included, A HPLC system (Agilent 1100 Series, Agilent 1100 Pump System with an Agilent 1100 adjustable Wavelength UV Detector), low speed centrifuge (B160A Medical), rapid mixer (SK-1), high speed disperser (GF-1), high speed benchtop centrifuge (TGL-10 ) and an electronic balance (Sartorius). This study was approved by the university ethics association.

The rat bacterial prostatitis model was established. The rats were subjected to fasting $12 \mathrm{~h}$ before experiment while free access to drinking water was provided. Abdominal anesthesia was given with sodium pentobarbital solution (3\%), and then the skin was prepared. An incision was made in the midline of the abdomen to the abdominal cavity, the

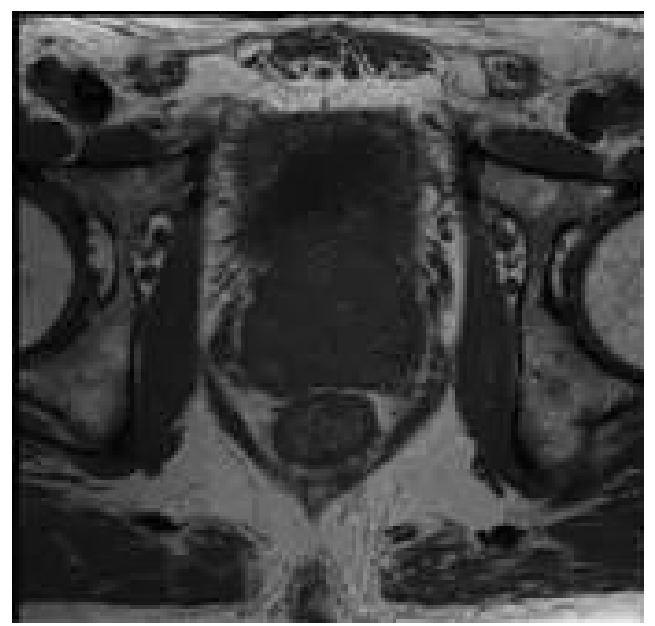

Fig. 1: The lesion of prostatitis bladder and bilateral seminal vesicles were elevated, and the prostate dorsal leaf attached to the outside of the bladder neck was fully exposed. Escherichia coli broth was injected into both sides of the rat prostate. The iodophor cotton ball was slightly pressed against the needle eye. Last, the abdominal wall muscle and skin were sutured, and the wound was disinfected with iodine. The rats were placed back in the cage. Five days later, bacterial prostatitis model was established, with success rate of $100 \%$. The rats were randomized into the control group and the research group, with 50 rats in each group. Levofloxacin solution $(44 \mathrm{mg} / \mathrm{kg})$ was injected intravenously to the rats of both groups. Terazosin hydrochloride solution was given by gavage to the rats of the research group at a dosage of $0.44 \mathrm{mg} / \mathrm{kg}$, which was performed one more time $12 \mathrm{~h}$ later. However, vehicle was administered by gavage to the rats of the control group twice. Five rats were sacrificed at different times after administration of levofloxacin. The prostate tissue was harvested and dried with a filter paper to weigh. The prostate tissue was placed in a test tube and chopped into pieces. Then physiological saline was added to prepare a tissue homogenate ${ }^{[6]}$. Finally, the drug content in the prostate tissue was measured.

First, the chromatographic behavior was observed. Under chromatographic conditions, the $t_{R}$ of levofloxacin in the prostate tissue homogenate was about $5 \mathrm{~min}$, which had a relatively ideal levofloxacin peak shape, as shown in fig. 2. Secondly, the standard curve, linear relationship and minimum quantifiable concentration were determined. Levofloxacin was added to the blank prostate homogenate to give a concentration of $12.2,6.1,3.05,1.525,0.7625,0.3812$ and $0.1906 \mu \mathrm{g} / \mathrm{ml}$, in order to obtain a standard curve in prostate matrix. Moreover, intraday and interday precision were measured. According to the method of sample processing, 3 standard concentrations of 12.2 , 3.05 , and $0.7625 \mu \mathrm{g} / \mathrm{ml}$ were selected and 4 samples were chosen to obtain the intraday and interday difference. Meanwhile, the recovery rate of this method was evaluated, as shown in Table 1. Finally, the freezer

TABLE 1: THE INTRADAY AND INTERDAY PRECISION AND LEVOFLOXACIN RECOVERY

\begin{tabular}{lcccccc}
\hline \multirow{2}{*}{$\begin{array}{l}\text { Concentration } \\
(\mu \mathrm{g} / \mathrm{ml})\end{array}$} & \multicolumn{2}{c}{ Intraday difference } & \multicolumn{2}{c}{ Interdaydifference } & \multicolumn{2}{c}{ Levofloxacin recovery } \\
\cline { 2 - 7 } & $\begin{array}{c}\text { Actual } \\
\text { concentration } \\
(\mu \mathrm{g} / \mathrm{ml})\end{array}$ & RSD $(\%)$ & $\begin{array}{c}\text { Actual } \\
\text { concentration } \\
(\mu \mathrm{g} / \mathrm{ml})\end{array}$ & RSD $(\%)$ & $\begin{array}{c}\text { Recovery rate } \\
(\%)\end{array}$ & \\
12.2 & $12.9 \pm 0.9$ & 6.6 & $12.4 \pm 0.2$ & 8.2 & $90.27 \pm 0.60$ & 0.8 \\
3.05 & $3.10 \pm 0.3$ & 6.6 & $3.08 \pm 0.5$ & 9.9 & $96.58 \pm 0.82$ & 0.9 \\
0.7625 & $0.7893 \pm 0.0256$ & 6.2 & $0.7673 \pm 0.0528$ & 6.5 & $105.83 \pm 10.29$ & 10.5 \\
\hline
\end{tabular}


stability was observed, repeated freezing and thawing of the prostate tissue homogenate was performed. Then the test was made after management. The result showed that the prostate tissue homogenate has relatively high stability in measuring levofloxacin within $5 \mathrm{~d}$ under repeated freeze-thaw management.

Statistical analysis was performed using SPSS21.0. All quantitative data were expressed in the form of mean \pm standard deviation, and comparisons were made with t-test. Enumeration data were expressed in the form of natural number (n)+percentage (\%), and comparisons were made with chi-square test. $\mathrm{P}<0.05$ represents the intergroup difference was of statistically significance.

As shown in Table 2, results showed that levofloxacin concentration in the prostate at different time points was significantly elevated in the research group, compared to the control group $(p<0.05)$. As shown in Table 3, there was significant difference in the drug concentration of different time period between both the groups $(p<0.05)$.

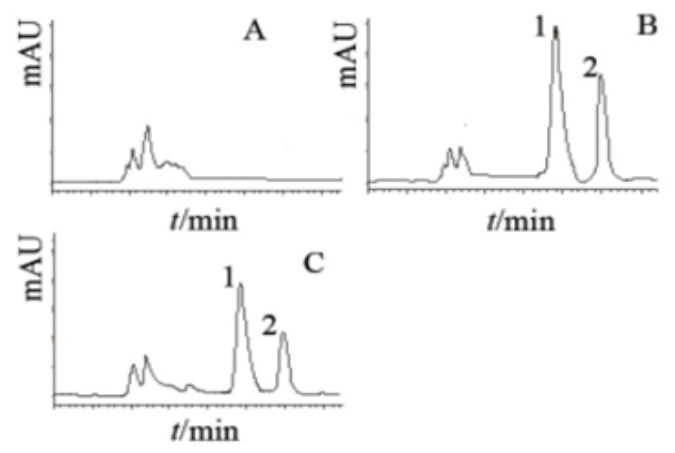

Fig. 2: Chromatographic analysis of drug concentration $A, B$ and $C$ respectively indicate blank prostate tissue homogenate, prostate homogenate+levofloxacin+norfloxacin, 1 hour after drug administration, 1. levofloxacin, 2. norfloxacin
In recent years, combination therapy of antibiotics and $\alpha 1$-adrenergic receptor blockers were generally applied in the treatment of prostatitis, which can yield favorable results. Of those, combination regimen of terazosin hydrochloride and levofloxacin have been widely used ${ }^{[7,8]}$. Currently, research had shown that the theory to explain the pathogenesis of prostatitis (fig. 3) is urinary reflux. This situation would occur if the $\alpha$-adrenergic receptor was stimulated, which could further bring prostatitis. Terazosin could effectively reduce the urethral pressure and alleviate urinary reflux. Therefore, the combination of both drug could fully exert therapeutic effect.

The results of this study proved that terazosin can not only increase the concentration of levofloxacin in the prostatitis tissue, but also advance the peak concentration, obtain a longer half-life period, reduce the clearance rate and increase the duration of effective drug concentration. There is an abundance of $\alpha$-adrenergic receptors in the prostate matrix and

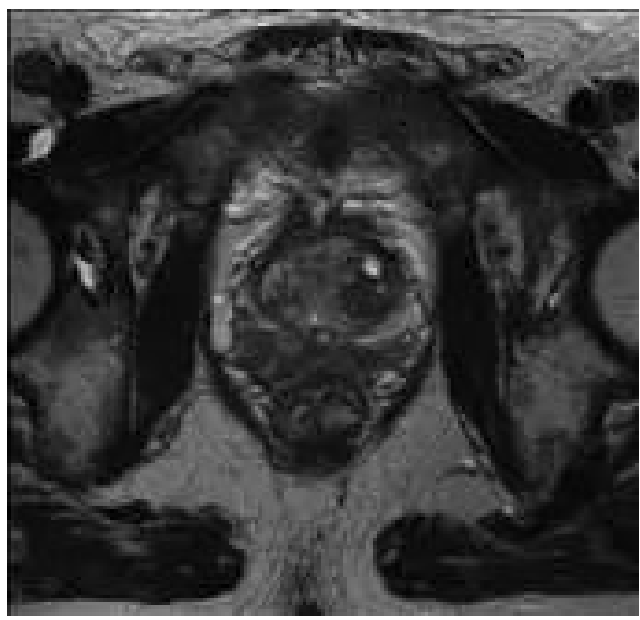

Fig. 3: Image of prostatitis

TABLE 2: COMPARISON OF THE LEVOFLOXACIN CONCENTRATION IN THE PROSTATE AT DIFFERENT TIME POINTS BETWEEN BOTH GROUPS

\begin{tabular}{lccccccc}
\hline Groups & $1 \mathrm{~min}$ & $\mathbf{1 5} \mathrm{min}$ & $\mathbf{3 0} \mathrm{min}$ & $\mathbf{6 0} \mathrm{min}$ & $\mathbf{1 2 0} \mathrm{min}$ & $\mathbf{4 8 0} \mathrm{min}$ & $\mathbf{7 2 0} \mathrm{min}$ \\
\hline Research group & $17.29 \pm 0.63$ & $120.8 \pm 27.40$ & $88.05 \pm 16.65$ & $79.22 \pm 19.01$ & $69.04 \pm 15.34$ & $32.13 \pm 10.56$ & $3.94 \pm 0.67$ \\
Control group & $6.18 \pm 0.67$ & $95.09 \pm 25.36$ & $66.12 \pm 22.30$ & $56.28 \pm 19.00$ & $36.99 \pm 13.20$ & $4.89 \pm 1.94$ & $1.78 \pm 0.52$ \\
$\mathrm{t}$ & 10.93 & 17.89 & 9.37 & 11.29 & 15.66 & 20.18 & 10.35 \\
$\mathrm{P}$ & $<0.05$ & $<0.05$ & $<0.05$ & $<0.05$ & $<0.05$ & $<0.05$ & $<0.05$ \\
\hline
\end{tabular}

Mean \pm standard deviation

TABLE 3: PHARMACOKINETICS OF LEVOFLOXACIN IN THE PROSTATE OF RAT MODEL OF BACTERIAL PROSTATITIS

\begin{tabular}{lccccc}
\hline Groups & $\mathrm{t} 1 / 2 \mathrm{~B}(\mathrm{~h})$ & $\mathrm{t} \max (\mathrm{h})$ & $\mathrm{Cmax}(\mu \mathrm{g} / \mathrm{g})$ & $\mathrm{AUC0}-12(\mu \mathrm{g} \cdot \mathrm{h} / \mathrm{g})$ & $\mathrm{CL}(\mathrm{g} / \mathrm{h})$ \\
\hline Research group & $6.58 \pm 2.69$ & $0.20 \pm 0.10$ & $148.51 \pm 40.23$ & $610.29 \pm 220.78$ & $0.06 \pm 0.01$ \\
Control group & $2.12 \pm 0.75$ & $0.98 \pm 0.20$ & $73.22 \pm 22.19$ & $255.678 \pm 90.72$ & $0.36 \pm 0.02$ \\
$\mathrm{t}$ & 7.04 & 6.58 & 9.01 & 5.66 & 6.27 \\
$\mathrm{P}$ & $<0.05$ & $<0.05$ & $<0.05$ & $<0.05$ & $<0.05$ \\
\hline
\end{tabular}

Mean \pm standard deviation 
capsule, more than $70 \%$ of which are $\alpha 1 \mathrm{~A}$ subtypes. Smooth muscle will contract when the receptors are excited, leaving the prostate tissue in a state of tension.

Terazosin, a novel highly selective $\alpha 1$ receptor blocker could relax the smooth muscle in the prostate and effectively dilates the blood vessels, thus increasing blood flow and the antimicrobial drug concentration of the tissue. Therefore, terazosin could increase the levofloxacin level in prostatitis tissues and assist levofloxacin in the treatment of prostatitis. By combination therapy, it can improve the prognosis and thereby the qhality of life of the patients. The results of this study were inline with many studies, which can provide valuable basis for clinical treatment ${ }^{[9-16]}$.

To sum up, prostatitis is a disease of high incidence, with relatively complicated pathogenic factors, which has a certain impact on the patient's work and life. Ideal effects couldn't be obtained by single medication, and it is easy to cause disease progression. Therefore, it is of great importance to adopt combination therapy which is more effective. The current application of terazosin combined with levofloxacin is relatively common. In this study, the effects of terazosin on the pharmacokinetics of levofloxacin in the treatment of prostatitis were evaluated in a rat model. HPLC method was used to determine levofloxacin level in the tissue, which has high detection accuracy. Meanwhile, levofloxacin hydrochloride and impurity peaks were well separated under the chromatographic conditions. Results showed that terazosin can not only significantly increase the levofloxacin level in prostatitis, but also enhance its peak concentration, increase halflife, positively increase blood flow, and improve the distribution of levofloxacin in tissues.

\section{REFERENCES}

1. Zhao J, Xiao MC, Zhou YD. Effect of terazosin on the distribution of levofloxacin in rat bacterial prostatitis. Chin J New Drugs Clin Med 2016;29(03):199-202.

2. Liu J, Hu W, Sun SB. Effect of terazosin on the distribution of levofloxacin in rat prostatitis. Lab Med Clin 2017;7(14):14202 .

3. Zeng Y, Xiao MC, Zhou YD. Effect of terazosin hydrochloride on plasma concentration of levofloxacin in rats with bacterial prostatitis. Chin Pharm 2016;22(05):408-10.

4. Iwata $\mathrm{H}$, Masuda $\mathrm{N}$, Ohno S, Rai $\mathrm{Y}$, Sato $\mathrm{Y}$, Ohsumi $\mathrm{S}$, et al. A randomized, double-blind, controlled study of exemestane versus anastrozole for the first-line treatment of postmenopausal Japanese women with hormone-receptor-positive advanced breast cancer. Breast Cancer Res Treat 2016;139(2):441-51.

5. Lee DS, Kim SH, Kim S, Suh YJ, Kim HK, Shim BY. Prognostic significance of breast cancer subtype and p53 overexpression in patients with locally advanced or high-risk breast cancer treated using upfront modified radical mastectomy with or without post-mastectomy radiation therapy. Int J Clin Oncol 2017;17(5):447-55.

6. Weng G. Efficacy of levofloxacin combined with terazosin hydrochloride in the treatment of 68 patients with chronic nonbacterial prostatitis. Pract Clin Med J 2017;17(07):141-3.

7. Cantey JB, Sreeramoju P, Jaleel M, Treviño S, Gander R, Hynan LS, et al. Prompt control of an outbreak caused by extendedspectrum $\beta$-lactamase-producing klebsiellapneumoniae in a neonatal intensive care unit. J Pediatr 2017;163(3):672-9.

8. Badal RE, Bouchillon SK, Lob SH, Hackel MA, Hawser SP, Hoban DJ. Etiology, extended-spectrum $\beta$-lactamase rates and antimicrobial susceptibility of gram-negative bacilli causing intra-abdominal infections in patients in general pediatric and pediatric intensive care units - Global data from the study for monitoring antimicrobial resistance trends 2008 to 2010. Pediatr Infect Dis J 2016;32(6):636-40.

9. Markovska RD, Stoeva TJ, Bojkova KD, Mitov IG. Epidemiology and molecular characterization of extendedspectrum beta-lactamase-producing enterobacter spp., pantoeaagglomerans, and serratiamarcescens isolates from a Bulgarian hospital. Microb Drug Resist 2017;20(2):131-7.

10. Peng H. Comparison of the efficacy of finasteride, tamsulosin and terazosin in the treatment of benign prostatic hyperplasia. Chin Pract Med 2017;12(21):111-3.

11. Xu K, He G, Qin J. High-Efficient Extraction of Principal Medicinal Components From Fresh Phellodendron Bark (Cortex Phellodendri). Saudi J Biol Sci 2018;25(4):811-5.

12. Khaliq S, Haider S, Siddiqui M, Sherwani SK, Sajid I, Mustafa $\mathrm{S}$, et al. Enhancement in Spatial and Recognition Memory Functions Following Long Term Oral Administration of Ginger Extract in Rats. Pak J Pharm Sci 2017;30(6):2061-6.

13. Al-Turki DA, Al-Omar MA, Abou-Zeid LA, Shehata IA, Al-Awady MS. Design, Synthesis, Molecular Modeling and Biological Evaluation of Novel Diaryl Heterocyclic Analogs as Potential Selective Cyclooxygenase-2 (Cox-2) Inhibitors. Saudi Pharm J 2017;25(1):59-69.

14. Precenzano F, Ruberto M, Parisi L. Executive Functioning in Preschool Children Affected by Autism Spectrum Disorder: A Pilot Study. Acta Med Med 2017;33(1):35-39.

15. Wavare SH, Gade RM, Shitole AV. Effect of Plant Extracts, Bio Agents and Fungicides Against Sclerotium Rolfsii Causing Collar Rot in Chickpea. Indian J Pharm Sci 2017;79(4):513-20.

16. Metin Ökmen B, Koyuncu E, Uysal B, Özgirgin N. The Effects of the Number of Physical Therapy Sessions on Pain, Disability, and Quality of Life in Patients with Chronic Low Back Pain. Turk J Med Sci 2017;47(5):1425-31.

This is an open access article distributed under the terms of the Creative Commons Attribution-NonCommercial-ShareAlike 3.0 License, which allows others to remix, tweak, and build upon the work non-commercially, as long as the author is credited and the new creations are licensed under the identical terms

This article was originally published in a special issue: Special issue on "Drug Development and Human Health in China"

Indian J Pharm Sci 2020:82(1)spl issue2;81-84 